ISSN 0104-4443

Licenciado sob uma Licença Creative Commons

\title{
Civilização, sexualidade e entropia no pensamento de Freud
}

\author{
Civilization, sexuality and entropy \\ in Freud's thought
}

\section{Christiane Carrijo Eckhardt Mouammar ${ }^{[a]}$, Francisco Verardi Bocca ${ }^{[b]}$}

[a] Doutora em Filosofia e docente do Departamento de Psicologia da UNESP, Bauru, SP - Brasil, e-mail: chris@fc.unesp.br

[b] Docente do Programa de Pós-graduação em Filosofia da PUCPR, Curitiba, PR - Brasil, e-mail: francisco.bocca@pucpr.br

\section{Resumo}

O presente artigo pretende oferecer de maneira introdutória uma reflexão visando à construção de uma interpretação do pensamento de Sigmund Freud, instrumentalizando noções como as de progresso da civilização, portanto o que seria sua filosofia da história; uma investigação quanto às suas concepções acerca da "natureza humana"; culminando numa breve reflexão sobre alguns pontos da filosofia da natureza que subjaz ao seu pensamento. Antecipamos que reconhecemos nessa última características que, por analogia, assimilamos ao conceito de entropia da física moderna. Dentre outros recursos, como a referência comparada e metodológica com algumas teses de Kant sobre as mesmas noções, também apresentamos de maneira recortada dois aspectos 
metapsicológicos da teoria freudiana sobre a sexualidade humana, o biológico e o fisiológico, ambos com o objetivo de dar subsídio às reflexões sobre sua noção de finalidade.

Palavras-chave: Psicanálise. Finalidade. Sexualidade. Pulsões. Entropia.

\section{Abstract}

This article intends to offer, in an introductory way, a reflection in order to build an interpretation of the Sigmund Freud's thought, orchestrating notions such as the ones of progress of civilization, which would be his philosophy of history; an investigation on his conceptions about "human nature"; culminating in a brief reflection on some points of philosophy of nature that underlies his thought. We anticipate that we recognize in the latter, characteristics assimilated by analogy to the entropy concept of modern physics. Among other features, such as compared and methodological reference with some of Kant's theses about the same notions, we also present in a short way two metapsychological aspects of Freudian theory on human sexuality, the biological and physiological, both aiming to give support to the reflections on the sense of finality.

Keywords: Psychoanalysis. Finality. Sexuality. Instincts. Entropy.

Neste artigo, a partir dos resultados de pesquisa obtidos até o momento, pretendemos oferecer uma interpretação do pensamento de Freud, referente a suas noções e concepções acerca da "natureza humana". Ainda de maneira complementar, e nesse ponto temos algo novo em nossa pesquisa, uma investigação sobre o que poderíamos chamar de sua filosofia da história. Para isso recorreremos a um tipo de contraposição a algumas teses de Immanuel Kant (1724-1804) sobre esse tema. Também, em reforço, discutiremos o ponto de vista biológico e o fisiológico da sexualidade humana, com o objetivo de dar subsídio às reflexões sobre sua noção de finalidade, e com isso pretendemos amarrar os temas da natureza humana e da sua história. Não satisfeitos ainda, de maneira mais ousada, investigaremos sua filosofia da natureza. Antecipamos que reconhecemos nela uma forte identificação ao conceito de entropia (segunda lei da termodinâmica) da física moderna. Evidentemente que todo esse conjunto de conceitos referidos deve dar 
sustentação à investigação que orienta nossa pesquisa, os estatutos e as nuances da noção de conservação da vida forjadas por alguns pensadores da modernidade e suas implicações para a psicanálise.

Pois bem, sabemos que em mais uma visita à história da filosofia moderna, podemos identificar na filosofia de $\mathrm{Kant}^{1}$ o reconhecimento de que há na razão humana uma doação da natureza com finalidade de aperfeiçoar a humanidade. Por sua vez Freud, em oposição, reconheceu na história da humanidade um desenrolar sucessivo de renúncia e de realização de desejo, conduzido por uma razão não dotada de dispositivos eficientes para imprimir no processo a mesma finalidade de aperfeiçoamento e progresso da humanidade. Até porque a civilização teria adquirido, em sua constituição dada no jogo ou conflito instintual, certas capacidades de esclarecimento e gestão dos instintos, mas também fraquezas e obstáculos como resultado desse embate. Vale dizer, um adoecimento progressivo, um mal-estar crescente em proporção à complexificação da civilização.

Segundo entendemos, esse fato comporta pelo menos duas saídas. Por um lado, uma atuação adaptativa que, mesmo que não se admita um lugar privilegiado de chegada, como telos, apresenta a possibilidade de imprimir um tipo de avanço ou melhora nas condições materiais e morais da humanidade, vale dizer, na produção de civilização. Por outro lado, podemos esperar uma consequência desastrosa, já que sem proporcionar recompensa pela renúncia que impôs e reconhecimento dessa recompensa, a civilização pode ser pensada como produtora de crescente mal-estar e infelicidade.

Seus leitores sabem que a primeira saída foi de certa forma pleiteada exemplarmente na obra O futuro de uma ilusão, de 1927, na qual expôs uma expectativa positiva e otimista em relação ao progresso científico e moral. Cremos que isso se deu em função de ter adotado um ponto de vista iluminista, isto é, a "crença" de que o exercício da racionalidade poderia promover um ultrapassar efetivo das disposições contrárias à promoção da existência civilizada, especialmente por dois

1 Para mais informações sobre os argumentos que se seguem, ver: BOCCA, F. V. Civilização, finalidade com exaustão. Kant e-Prints, v. 5, n. 1, p. 89-117, 2010. 
motivos: pela superação das ilusões religiosas e pelo caráter evolutivo e ascendente do espírito científico.

Contudo, essa aproximação com o Kant do esclarecimento não se sustentou por muito tempo. Isso pode ser reconhecido com recurso a obras, anteriores e posteriores, nas quais essas ideias foram relativizadas e as expectativas na razão degradadas ao ponto de permitir a concepção de uma história involutiva, ${ }^{2}$ pelo menos quanto às conquistas morais. Isso pode ser admitido quando se leva adiante uma leitura mais atenta de seus pressupostos, ou ainda, quando o leitor reconhece de maneira mais ousada a natureza do psiquismo enquanto palco de conflitos não sintetizáveis, justamente o que define o limite e o alcance de uma racionalidade promotora de ordem e progresso. Para avançarmos nessa compreensão, julgamos mais uma vez necessário apontar para algo mais fundamental que, segundo nosso entendimento, subjaz ao pensamento de Freud. Trata-se do que tomamos a licença de apontar como sendo sua própria filosofia da natureza, que reconhecemos como entrópica, a partir do que esperamos continuar tirando consequências e conclusões.

Para subsidiar aqui também nosso propósito, recordemos que o conceito de entropia, cunhado em 1850 por R. J. E. Clausius (1822-1888), recebeu contribuições, entre outros, de Maxwell e Boltzmann. Desde o início do século XIX conceberam a noção de que todo sistema físico evolui sempre e espontaneamente para situações de máxima entropia, ou seja, de máxima desordem. Reconheceram a tendência universal de todos os sistemas a passar de uma situação de ordem para a de uma crescente desordem, o que remete secundariamente à própria impossibilidade de conservação de alguma forma de energia, vale dizer, de vida.

Nesse contexto da física moderna, a conhecida como primeira lei da termodinâmica, que anuncia o universo como um sistema fechado e subsistente, acabou sendo, embora não de maneira contraditória, confrontada pela segunda lei, que concebe todo processo natural como irreversível. Essa última tem assim a pretensão de limitar e corrigir o primeiro enunciado ao considerar que a energia total do universo

2 Essa tese foi apresentada, por exemplo, em Reflexões sobre tempo de guerra e morte, de 1915. 
estaria sujeita a uma degradação em função de um contínuo aumento de desordem, que cresce enquanto decresce a ordem e por fim se estabiliza em definitivo no equilíbrio ou repouso. A energia total, nessa ótica, seria a responsável pela passagem do tempo, pelo envelhecimento e desgaste, num sentido irreversível, da matéria e da energia disponível.

Assim, entendemos por analogia que o aparelho psíquico e o conflito crescente que apresenta podem igualmente ser pensados como um sistema dessa natureza, ou seja, como usina de produção de desordem. Embora possamos reconhecer nele a presença de uma tendência a reduzir a tensão enquanto sustenta a vida, por exemplo, por complexificação da vida, não podemos deixar de reconhecer sua meta de satisfação, que é a de exauri-la, meta que antecede a tentativa de perenizá-la por algum modo.

Dessa forma, admitida a postulação do que seria sua filosofia da natureza segundo as características que lhe atribuímos, entendemos que os resultados a que Freud chegou foram possíveis justamente pela falta de uma teleologia positiva que ela comporta, ou ainda, pela adoção de uma teleologia entrópica, o que para nós se apresenta na forma de uma consideração da natureza e da história humana como uma mera acumulação de dados, cuja finalidade ainda precisa ser discutida. É verdade que essa suspeita não descarta, antes requer, uma lógica, o reconhecimento de uma dinâmica ou ordem interna de sustentação do conflito pulsional. Por ora nos inclinamos a reconhecê-la como trágica, isto é, sustentando um conflito insolúvel e crescente.

Posto isso, como prometido anteriormente, avançaremos nossas justificativas discutindo agora o conceito de pulsão a partir de dois pontos de vista: o fisiológico e o biológico. Com eles buscaremos reconhecer certas características da sexualidade humana com o propósito de dar sustentação a nossos argumentos. Quanto à fisiologia, no artigo "Pulsões e destinos de pulsão", de 1915, Freud retomou, entre outros, um ponto do manuscrito Projeto de uma psicologia científica, de 1895, além de A Interpretação de sonhos, de 1900, a saber, o esquema do arco-reflexo. Segundo este, um estímulo externo que atinge o tecido vivo da substância nervosa é novamente reconduzido para o exterior por meio de uma ação, uma ação motora de fuga. Dessa forma, o aparelho 
psíquico igualmente seguiria a lógica do arco-reflexo em relação aos estímulos externos e internos que o atingem.

Esse movimento está articulado à consideração básica de que toda estimulação é "interpretada" pela consciência como desprazerosa, por conta do que exige providências quanto à sua remoção, até porque essa perspectiva vem acompanhada da consideração de que toda estimulação tem como natureza ser irritativa, isto é provocar desprazer, ${ }^{3}$ o que faz dela algo primariamente e fundamentalmente identificada ao desprazer. Dessa forma, o aparelho psíquico, assim como o sistema nervoso, não teria outra incumbência se não a de funcionar segundo a meta do escoamento, da anulação de toda estimulação. No entanto, no caso da estimulação endógena, algo diverso parece ocorrer - até porque é de sua própria natureza exercer uma força ou pressão constante, o que impede seu escoamento imediato por uma ação qualquer. Isso porque o estímulo pulsional proveniente do interior do organismo exerce uma força constante, imprimindo uma necessidade. Nesse sentido, tudo aquilo que suspende o estado de necessidade proporciona sua satisfação, como afirmou Freud ([1915] 2004, p. 146) em Pulsões: “Essa satisfação só pode ser alcançada por meio de uma alteração direcionada e específica (isto é, adequada) da fonte interna emissora de estímulos", o que é alcançado por uma ação específica que proporciona sucesso na remoção ou anulação, ao menos por um intervalo, desse estímulo.

Assim, Freud esclareceu que para lidar com o excesso de estimulação externa o aparelho psíquico possui uma saída motora que promove sua fuga imediata. Já para lidar com os estímulos internos pulsionais tudo se complica para esse mesmo aparelho, pois sua pressão constante demanda adicionalmente a exigência de uma saída para a insistência de demanda que exerce. Desse modo, as pulsões movem o psiquismo, pressionam o organismo a encontrar saídas viáveis e, assim, impulsionam a própria vida no interior do aparelho psíquico enquanto viabilizam a tarefa do sistema nervoso de lidar com tais estímulos. Dessa forma,

3 Sobre a natureza negativa do prazer, consultar artigo de B0CCA, F. V. Prazer, psicanálise! Natureza Humana, v. 11, n. 1, p. 101-128, jan./jun. 2009. 
podemos reconhecer o ponto de vista fisiológico, apoiado inicialmente no modelo do arco-reflexo (estímulos externos) e, num segundo momento, na produção e gestão dos caminhos pulsionais (estímulos internos).

Tal ponto de vista demonstra como as pulsões abrem um caminho no interior do aparelho, buscando uma saída para a pressão constante, e assim o mobilizam. Por conta disso, para se livrar do excesso de energia pulsional, o aparelho psíquico providencia a transformação de energia física em energia psíquica. Para isso, o ponto de vista fisiológico (descarregar o excesso de estimulação) foi acrescido do ponto de vista econômico, conceito auxiliar (que trata da circulação da energia e do prazer e desprazer dela decorrente) para compreender a passagem da energia somática para a psíquica. Tudo isso nos estimula a elaborar uma interrogação: se nesse esquema o que importa é descarregar, por uma ação específica, o alto grau de excitação (não importando por meio de qual objeto, contanto que o objetivo de aliviar a pressão constante no psiquismo seja alcançado), em que medida e por quais critérios estamos autorizados a considerar um comportamento sexual como normal ou como patológico?

Sabemos que é frequente na obra Três ensaios sobre a teoria sexual, de 1905, a prática de recorrer à biologia e nisso atingir resultados divergentes dos estabelecidos por essa ciência no fim do século XIX com relação ao que seria o comportamento sexual normal do gênero humano. Ora, se do ponto de vista fisiológico toda variação de recurso a objetos foi considerada normal, isso equivale a admitir uma ampla variação no campo de possibilidades da vida sexual, o que a situa no campo da multiplicidade e indeterminação. Nesse caso, uma conduta sexual considerada patológica só poderia ser fundamentada de um ponto de vista cultural, vale dizer, ideológico. Nessa obra, acreditamos que Freud não abandonou, por não concordar inteiramente com esse último ponto de vista, seus argumentos naturalistas.

No entanto, Freud ao mesmo tempo admite a finalidade da pulsão sexual como meta biológica reprodutiva pelo encontro de genitais opostos. Em decorrência dessa meta reprodutiva admitida, deu sua contribuição para a definição das condições gerais em que um comportamento sexual poderia ser considerado anormal. Definiu que ele 
ocorre quando o anseio por um fetiche, entendido como substituto do órgão sexual genital - como uma parte do corpo pouco apropriada para fins sexuais ou ainda um objeto inanimado -, se fixa e substitui o alvo sexual reprodutor e, mais, quando ele se torna o único objeto sexual. Nesse caso, deixa claro que a meta da pulsão é a satisfação de sua necessidade sexual, mas que essa satisfação não se dá exclusivamente ou necessariamente com vistas à procriação.

Dessa forma, nos Três ensaios a recusa da procriação como objetivo último da finalidade sexual, bem como a falta de necessidade do coito genital, que justifica a anormalidade, se fizeram acompanhar do reconhecimento da procriação como uma função legítima da sexualidade humana. Assim, sua biologia, ao mesmo tempo em que explica a transgressão do "normal" vigente através da variabilidade do objeto ponto de vista fisiológico -, também, de certa maneira, estabelece a norma. Citando Freud ([1905] 1996, p. 153):

quando a perversão não se apresenta ao lado do alvo e do objeto sexuais normais, no caso em que a situação é propícia a promovê-la e há circunstâncias desfavoráveis impedindo a normalidade, mas antes suplanta e substitui o normal em todas as circunstâncias, ou seja, quando há nelas as características de exclusividade e fixação, então nos vemos autorizados, na maioria das vezes, a julgá-la como um sintoma patológico.

Bem, a questão fica assim ampliada, pois afinal de onde emana o estabelecimento da norma: da natureza biológica ou da cultura, ou de ambos? Mas a pergunta vai adiante e, para ser respondida, exige uma resposta a um questionamento anterior: se há uma finalidade ou teleologia na sexualidade humana, admitida nos Três ensaios, e que dê sentido ao comportamento sexual e o encaminhe em direção a uma meta reprodutiva para a espécie humana. Acreditamos que nosso questionamento se justifica, até porque a hipótese da subordinação da sexualidade infantil polimorfa à sexualidade adulta genital não garante, a não ser aparentemente, um resultado finalista ou teleológico de procriação e conservação da humanidade; antes, o dificulta.

Refletindo sobre os pontos de vista fisiológico e biológico, podemos concluir que, se o mandato da fisiologia é a descarga, a 
normatização viria do lado do social. Ou seja, desse ponto de vista, como o objeto é variável e o comportamento sexual humano, caracterizado pela plasticidade, a nomeação da patologia seria dada pela cultura; portando, não confere nenhuma finalidade de procriação ou conservação da vida e da espécie. Por outro lado, se há de fato uma teleologia reprodutora nos Três ensaios, ela caminha no sentido da pulsão sexual estar atrelada ao biológico reprodutivo visando à conservação da espécie, isto é, a sexualidade entendida como um construto da espécie.

Seu complicador é que a fisiologia permite que essa mesma sexualidade seja entendida como um construto do indivíduo, pela ampla possibilidade e necessidade que o psíquico tem de abrir/construir caminhos individuais para encontrar saídas para a descarga pulsional. Portanto, a demanda de descarga estará sempre no horizonte de constituição do aparelho psíquico e na orientação da sexualidade, o que, de certa forma, deve-se admitir, obstaculiza a meta biológica da procriação.

A partir dessas considerações acerca da natureza nuançada e talvez contraditória da sexualidade concebida por Freud, sentimo-nos autorizados a levar em conta que essa falta de uma determinação e de uma finalidade positiva na sexualidade humana como construto do indivíduo permitiu a ele considerar a sexualidade naturalmente sustentada e orientada na equivocidade do desejo.

Explorados os pontos de vista fisiológico e biológico, procuraremos extrair mais consequências aprofundando a articulação entre suas noções de sexualidade, natureza e história. Para isso lembremos que, se em Kant, a suposta teleologia da natureza extensiva ao homem, promove, lembra Perez (2006, p. 83), a passagem “do orgânico para o racional e finalmente moral", por sua vez, em Freud ocorre por toda parte uma espécie de teleologia invertida, auxiliada pela sexualidade, que conduz do inorgânico ao inorgânico. Tal perspectiva foi apresentada com todas as letras em 1920, na obra Além do princípio do prazer, imprimindo um movimento que descreve um arco de retorno à condição original, para o qual contribui o puro jogo instintual, vale dizer o próprio princípio do prazer, que evidencia o "sem sentido" da duração da vida, ou que de outra forma lhe aponta o sentido da exaustão, expressando a nítida 
perspectiva entrópica que subsidia seu pensamento. A importância dessa obra justifica a apresentação de algumas de suas teses.

Nela, Freud ([1920] 1969, p. 47) reconheceu o que chamou de um atributo universal dos instintos, estendendo-o à própria vida orgânica:

um instinto é um impulso inerente à vida orgânica, a restaurar um estado anterior de coisas, impulso que a entidade viva foi obrigada a abandonar sob a pressão de forças perturbadoras externas, ou seja, é uma espécie de elasticidade orgânica, ou, para dizê-lo de outro modo, a expressão da inércia inerente à vida orgânica.

De início, pelo aspecto conservador que atribuiu ao instinto, fica evidente que este contraria a noção de conservação entendida como sustentação, como desenvolvimento e especialmente progresso, já que contém a hipótese de que exerce sua pressão no sentido da restauração de um estado anterior das coisas de que são instintos.

Segundo Freud, buscam um estado de coisas pretérito do qual toda substância viva se afastou e ao qual, depois disso, procura retornar. Trata-se do estado inorgânico, o que lhe permite dizer que o objetivo da vida é a morte, em função do que "tudo o que vive morre por razões internas" (FREUD, [1920] 1969, p. 49). Um argumento desses foi justificado sustentando que a vida só pode ter sido decorrência de uma evocação na matéria inanimada provocadora de uma tensão que passa a receber da matéria agora viva um esforço por neutralizá-la, escoá-la, exauri-la. Dessa maneira, disse, "surgiu o primeiro instinto: o instinto a retornar ao estado inanimado" (FREUD, [1920] 1969, p. 49).

Por conta disso, a hipótese de um instinto primário de conservação da vida, que atuaria em sua oposição e resistência, perde toda possibilidade. Na verdade não seria mais do que um veículo garantidor de que todo organismo vivo atinja por caminhos próprios sua meta de morte, sendo ela o produto de toda satisfação. Dessa forma, todo ser vivo se equilibra entre as duas classes de instintos, primariamente os lacaios da morte e secundariamente (e já fadados ao fracasso) os guardiões da vida.

Os instintos sustentadores da vida, identificados inicialmente como sexuais, seriam os responsáveis pela ilusão de que na luta contra 
a morte poderiam obter êxito, na medida em que pudessem conduzir o ser vivo a uma condição adaptada, evoluída, isto é, que atuassem na forma de um impulso em direção a um progresso, em um sentido de desenvolvimento superior pela via de ligações constantes. Essa perspectiva foi acompanhada de uma reflexão crítica curiosa, segundo a qual se trata apenas de, disse Freud ([1920] 1969, p. 52), “uma questão de opinião o fato de declararmos que determinado estágio de desenvolvimento é superior a outro". Com um ponto de vista em parte darwinista, rechaça a hipótese de que exista em ação no homem, e na natureza, um instinto para a perfeição, que seria o responsável por um elevado estágio de organização dos organismos, de realização intelectual e de elevação moral. Sobre isso declarou taxativamente: "não tenho fé na existência de tal instinto interno e não posso entender porque essa ilusão benévola deva ser conservada" (FREUD, [1920] 1969, p. 52). Tal ilusão no sentido de maior perfeição, explicou, seria resultado do desamparo fundamental que acomete todo ser humano, da própria repressão instintual que alicerça a civilização, bem como no conflito dela decorrente.

Assim, procuramos sustentar a possibilidade de a natureza, pela tendência de decaimento ao inorgânico que supostamente apresenta, comunicar aos homens um propósito semelhante e com semelhante finalidade, fatalista mesmo para a vida, imprimindo em sua constituição psíquica igual propósito. Isso admitido, estariam todos os homens, a despeito de se darem conta ou de concederem ao seu propósito, cumprindo coletivamente as determinações da natureza. Nesse caso, a natureza do conflito psíquico, sua sustentação ininterrupta e inclusive seu agravamento estariam em acordo com a produção entrópica de acúmulo de desordem e visaria assim ao decaimento, ao equilíbrio estático, à neurose progressiva e à morte como destino, o que pode ser reconhecido na crescente produção de mal-estar na vida de cada indivíduo e da civilização.

Por fim, parece que, no limite, num primeiro momento, Kant e Freud convergem. Esperamos estar justificados, no reconhecimento de uma teleologia natural, contando com dispositivos naturais de determinação e condução da vida. É verdade que depois divergem quanto ao fim alcançado, o que implica um intermediário (a existência cotidiana), também diverso. Se para Kant a possibilidade de construção e 
gratificação pela vida moral e civil rumo, quem sabe, a uma sociedade cosmopolita, que ofereça a possibilidade de convívio segundo uma paz perpétua, para Freud ([1920] 1969, p. 74), a doação da vida não é mais do que receber o encargo de construir com toda limitação possível a civilização, enquanto com isso atende à máxima de seu reitor, o princípio do prazer, que, segundo ele, "parece, na realidade, servir aos instintos de morte".

\section{Referências}

FREUD, S. Três ensaios sobre a teoria da sexualidade. Rio de Janeiro: Imago, 1996. v. 7. Publicado originalmente em 1905.

FREUD, S. Além do princípio do prazer. Rio de Janeiro: Imago, 1969. Publicado originalmente em 1920.

FREUD, S. Pulsões e destinos da pulsão. In: FREUD, S. Obras psicológicas de Sigmund Freud: escritos sobre a psicologia do inconsciente. Coordenação de tradução de Luiz Alberto Hanns. Rio de Janeiro: Imago, 2004. v. 1. Publicado originalmente em 1915.

KANT, I. Idéia de uma história universal de um ponto de vista cosmopolita. São Paulo: Brasiliense, 1986.

KANT, I. Resposta à pergunta: que é esclarecimento? In: KANT, I. Textos seletos. Petróplois: Vozes, 2005. p. 63-64.

PEREZ, D. O. Os significados da história em Kant. Revista Philosophica, Lisboa, n. 28, p. 67-107, 2006.

Recebido: 08/06/2011

Received: 06/08/2011

Aprovado: $15 / 07 / 2011$

Approved: 07/15/2011 